This is a revised personal version of the text of the final journal article, which is made available for scholarly purposes only, in accordance with the journal's author permissions. The full citation is:

Walker, M., Zhang, Y., Heaven, S., Banks, C.J. (2009). "Potential errors in the quantitative evaluation of biogas production in anaerobic digestion processes". Bioresource Technology. 100(24) 6339-6346.

http://dx.doi.org/10.1016/j.biortech.2009.07.018,

\title{
Potential Errors in the Quantitative Evaluation of Biogas Production in Anaerobic Digestion Processes
}

\author{
Mark Walker, Yue Zhang, Sonia Heaven, Charles Banks
}

School of Civil Engineering and the Environment, University of Southampton, Highfield, Southampton, UK, SO17 1BJ.

Keywords: Anaerobic Digestion; Biogas Production; Volumetric Measurement; Gas Solubility and Permeation

\section{Abstract}

Errors that are commonly made in the quantification of biogas from anaerobic digestion experiments were investigated.

For liquid displacement gasometers where a barrier solution separates the biogas and the atmosphere, inaccuracy due to gas diffusion was examined experimentally. Acidified saturated saline solution was the most suitable barrier solution, as biogas characteristics changed least with time. Using acidified or tap water caused considerable biogas losses and should therefore be avoided where biogas is stored before measurement.

Errors associated with volume calculation from three common liquid displacement gasometer types were investigated theoretically. Corrections that must be made to obtain gas volumes at standard temperature and pressure when using this equipment are discussed. Regarding experimental errors, gasometer designs where displaced liquid is weighed to determine the volume are the most versatile since errors depend mainly upon balance sensitivity. Using liquid heights to calculate volume requires appropriate sizing of the gasometer relative to the volume of gas measured.

The calibration of a low flow gas meter was investigated and an approximately linear variation with flow rate was found; hence in-situ calibration is advised for this type of instrument. Correction for atmospheric conditions should be performed in real time to reduce errors.

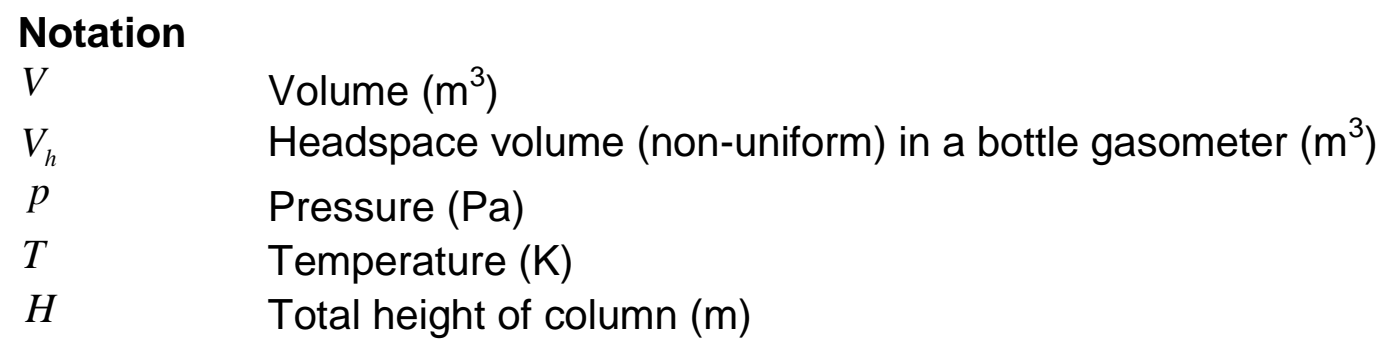


$m_{b} \quad$ Mass of barrier solution $(\mathrm{kg})$

$\rho \quad$ Density $\left(\mathrm{kg} \mathrm{m}^{-3}\right)$

1,2,stp,atm,b,t,c Subscripts refer to condition 1, condition 2, standard temperature and pressure, atmospheric, barrier solution, trough and column respectively.

\section{Introduction}

In research on anaerobic digestion the production of biogas and/or methane is one of the most important parameters, not only because of its economic value but also as it is related to substrate degradation and has been used for many years in the derivation of kinetic models (McCarty 1964). Despite this, there are many examples in the scientific literature where the methods of collecting, storing, measurement and calculation of biogas or methane volumes are poorly reported and potentially subject to quite large errors. A simple test to show this involved an ISI Web of Knowledge search of the last five published academic papers in the field of anaerobic digestion that quote gas production volumes. This revealed that only one reported correction of gas volumes to standard conditions, and in this particular case those conditions were also reported (Luostarinen et al. 2009). A further search revealed that even when gas volumes are reported as corrected to standard temperature and pressure (STP), more often than not the standard conditions are not given. Yet there are currently several definitions of STP in widespread use, with standard temperatures between 0 and $25^{\circ} \mathrm{C}$ and standard pressures between 100 and 101.325 $\mathrm{kPa}$, quoted in a variety of units. As an extreme example, using the former International Union of Pure and Applied Chemistry definition of $0{ }^{\circ} \mathrm{C}$ and $101.325 \mathrm{kPa}$ (McNaught and Wilkinson 1997) and the National Bureau of Standards definition of $25{ }^{\circ} \mathrm{C}$ and $100 \mathrm{kPa}$ (NBS 1982) gives a volume difference of more than $10 \%$ for the same mass of gas.

A common method of biogas collection is by liquid displacement. Gasometers of this type are used for general laboratory-based volume measurement because they are inexpensive, easy to set up and use, robust and capable of working for long periods without maintenance, and can be connected to data acquisition systems. The use of displacement gasometers requires that measurements taken directly from the gas column (e.g. liquid levels, pressure) are used to calculate gas volumes. As well as adjusting to STP, it is also necessary to take into account the vapour content and to make a correction for any hydrostatic pressure on the gas.

Consideration must also be given to the type of liquid used in the gasometer (the 'barrier solution'), which can be selected either to minimise solubility of the gases or to maximise the solubility of one component. In the first case, some sources simply recommend the use of acidified water (e.g. (BS 2004; EA 2005)), where others suggest adding salinity (Kida et al. 2001), and still others a combination of both acidity and salinity (Yang and Speece 1986; Soto et al. 1993; Schonberg et al. 1997; Sponza 2003; BS 2005). In the second case, alkaline solutions have been used to absorb carbon dioxide where quantification of methane only is required (Soto et al. 1993; Sponza 2003). Although alkaline conditions reduce the loss of gases by diffusion through the barrier solution they cannot prevent it entirely. Difficulties with all of these approaches have been noted by previous authors (Rozzi and Remigi 2004), but there is little published information on the magnitude of the errors due to loss of gas volume with different barrier solutions.

Another method for collection of biogas is in gas sampling bags with extremely low permeability. This avoids the problem of absorption during long periods of contact with a 
barrier solution, but measurement of the gas volume still depends on accurate correction for temperature and pressure depending on the method adopted.

An alternative to liquid displacement is the use of manometric methods, commonly used when dealing with production of low volumes of gas (James et al. 1990; Soto et al. 1993). The main drawback of the manometric approach is that variation in the pressure of the headspace gases alters the quantity dissolved in the liquid phase, especially in the case of carbon dioxide, which in turn can alter the $\mathrm{pH}$ and affect the experimental conditions (Rozzi and Remigi 2004).

In some circumstances (e.g. semi-continuous or continuously fed digestion experiments) it may be desirable to measure gas production rates using a gas flow meter. A number of different designs are available depending on the flow rate to be measured. For large-scale commercial applications flow meters may have automatic built-in correction for temperature and pressure, but this is rarely the case in equipment designed for laboratory use or for measurement at low flow rates. One of the most common types of low flow gasometer makes use of the 'tipping bucket' principle in which liquid is displaced by gas in a specially-designed chamber (e.g. (WRC 1975; Smith and Carliell-Marquet 2008)). Another type will detect the liquid level in a calibrated chamber before automatic discharge via a siphon or solenoid valve (e.g. (Nilsson et al. 1988; Liu et al. 2004)). Both of these approaches are influenced by the same factors as encountered in liquid displacement gasometers.

The experiments and theoretical considerations described in the paper are designed to highlight the problems associated with gas flow measurement, to present in a unified way the standard correction factors that need to be applied, and to provide guidance on the choice of barrier solutions and gasometer types for this purpose.

\section{Materials and Methods}

\subsection{Equipment}

\subsubsection{Gasometers}

Three types of liquid displacement gasometer were used in this work. Figure 1 shows those referred to respectively as the height and weight types. In the height gasometer, a closed cylinder or column is partially submerged in an open container of the barrier solution. Gas is introduced into the column via either the top valve (e.g. when emptying a collection bag) or the bottom valve (e.g. when connected directly to a digester), and displaces the barrier solution into the container. The volume of gas introduced can be calculated from measurements of the change in liquid height in the column and container. In some designs the level of the liquid in the container is maintained constant by provision of an overflow ensuring that the inlet to the gasometer remains at a constant pressure relative to ambient.

The weight gasometer is used for measurement of the volume in a gas sampling bag. In this type of gasometer, a column of liquid is located over a collection vessel. The volume of gas is introduced through a valve at the top of the column and liquid drains into the collection vessel. The liquid is then weighed and this measurement together with the height of liquid in the column can be used to calculate the volume of gas.

The third commonly used gasometer design is shown in Figure 2, and is referred to as the Bottle gasometer. In this type, the gas displaces the barrier solution from a sealed bottle into a second open container, and the volume is determined either by weighing the displaced liquid or by measuring the change in heights. 


\subsubsection{Continuous gas flow meter}

The gas flow meter used in this work was built to a design reported by the Water Research Centre (WRC 1975), which is typical of those commonly used in laboratories (Figure 3). The device works by means of an inverted tipping bucket immersed in liquid. As the gas bubbles fill the bucket it tips and a magnet activates a reed switch connected to a counting device. The flow meter used in this work had a nominal bucket volume of $20 \mathrm{ml}$ per count and was designed to measure gas flow rates of between $1-20$ litres day ${ }^{-1}$.

\subsubsection{Governing equations}

From hydrostatic relations and the equation of state, the equations governing height, weight and bottle type gasometers can be derived and are shown in equations 1,2 and 3 respectively. Equation 4 shows a rearrangement of equation 3 to allow the use of weight measurements for volume calculation in the bottle gasometer. A number of assumptions are made in the derivations: the cross-sectional areas of the columns/bottles and reception containers are constant; biogas acts as a perfect gas; once leaving the anaerobic digester biogas quickly cools to ambient temperature; the biogas is saturated with vapour, and the saturated vapour pressure (SVP) can be modelled by the Goff-Gratch equation as shown in equation 5 (Goff and Gratch 1946).

$$
V_{s t p}=\frac{T_{s t p} A}{T_{a t m} p_{s t p}}\left(\left(p_{a t m}-p_{H_{2} O}\left(T_{a t m}\right)-\rho_{b} g\left(h_{t 2}-h_{c 2}\right)\right) h_{c 2}-\left(p_{a t m}-p_{H_{2} O}\left(T_{a t m}\right)-\rho_{b} g\left(h_{t 1}-h_{c 1}\right)\right) h_{c 1}\right)
$$

Equation 1 Height Gasometer Governing Equation

$$
V_{s t p}=\frac{T_{s t p} A}{T_{a t m} p_{s t p}}\left[\left(\left(p_{a t n}-p_{H_{2} O}\left(T_{a t m}\right)+\rho_{b} g\left(H-h_{1}-\frac{m_{b}}{A \rho_{b}}\right)\right)\left(h_{1}+\frac{m_{b}}{A \rho_{b}}\right)\right)-\left(p_{a t n}-p_{H_{2} O}\left(T_{a t m}\right)+\rho_{b} g\left(H-h_{1}\right)\right) h_{1}\right]
$$

Equation 2 Weight Gasometer Governing Equation

$$
V_{s t p}=\frac{T_{s t p}}{T_{a t m} p_{s t p}}\left(\left(p_{a t n}-p_{H_{2} O}\left(T_{a t m}\right)+\rho_{b} g\left(h_{2}+h_{0}\right)\right)\left(A h_{2}+V_{h}\right)-\left(p_{a t n}-p_{H_{2} O}\left(T_{a t m}\right)+\rho_{b} g\left(h_{1}+h_{0}\right)\right)\left(A h_{1}+V_{h}\right)\right)
$$

\section{Equation 3 Bottle Gasometer Governing Equation (Height-based Calculation)}

$$
V_{s t p}=\frac{T_{s t p}}{T_{a t m} p_{s t p} \rho_{b}}\left(m_{b 2}-m_{b 1}\right)\left(p_{a t m}-p_{H_{2} O}\left(T_{a t m}\right)+\rho_{b} g\left(h_{0}+h_{1}+h_{2}+V_{h} / A\right)\right)
$$

Equation 4 Bottle Gasometer Governing Equation (Weight-based Calculation)

$$
\begin{aligned}
& p_{\mathrm{H}_{2} \mathrm{O}}(T)=101324.6 \times 10^{z} \\
& z=-7.90298\left(\frac{373.16}{T}-1\right)+5.02808 \log _{10}\left(\frac{373.16}{T}\right)-0.00000013816\left(10^{\left(11.34\left(1-\frac{373.16}{T}\right)\right)}\right) \\
& +0.00813289\left(10^{\left(-3.4914\left(^{\left(\frac{373.16}{T}-1\right)}\right)\right.}-1\right)
\end{aligned}
$$




\subsection{Experimental design}

\subsubsection{Testing of barrier and absorption solutions}

Barrier solutions were tested in height gasometers under static batch conditions. The gasometers consisted of a closed glass column with internal cross-sectional area of 36 $\mathrm{cm}^{2}$ and height $70 \mathrm{~cm}$, inverted in a glass container with an open surface area of $218 \mathrm{~cm}^{2}$. The barrier solutions used were tap water, acidified water $(\mathrm{pH} 2)$, saturated $\mathrm{NaCl}$ solution, acidified saturated $\mathrm{NaCl}$ solution $(\mathrm{pH} 2)$ and mineral oil, tested over a 17-day period. The effect of ionic strength was also investigated using barrier solutions of $25 \%, 50 \%, 75 \%$ and $100 \%$ saturated acidified $\mathrm{NaCl}(\mathrm{pH} 2)$ over an 8-day period. A standard biogas mixture (65\% methane and $35 \%$ carbon dioxide) was introduced into a gasometer containing each of these barrier solutions, and the biogas volume and composition in the column were then monitored daily.

$3 \mathrm{M} \mathrm{NaOH}$ was also used as a test solution for direct assessment of the methane content of the biogas mixture over an 8-day period.

\subsubsection{Sensitivity analysis on the quantification of biogas volume in gasometers}

Gas volumes calculated using Equations 1-4 were assessed for their sensitivity to correction for the vapour content, the pressure head due to the height of liquid in the gasometer relative to atmospheric pressure, and errors/irregularities in the column crosssectional area. In each case a range of aspect ratios $(\mathrm{H} / \mathrm{A})$ and cross-sectional areas were considered. Finally, the effect on gas volume of likely errors in the measurement of height (e.g. $1 \mathrm{~mm}$ ) and weight (e.g. $10 \mathrm{~g}$ ) was considered for gasometers of varying aspect ratio.

Unless otherwise stated, the following values were used in calculations: $A=158 \mathrm{~cm}^{2}, H=$ $0.66 \mathrm{~m}, \rho_{b}=1000 \mathrm{~kg} \mathrm{~m}^{-3}, h_{c 1}=0.1 \mathrm{~m}, h_{c 2}=0.4 \mathrm{~m}, h_{t 1}=0.6 \mathrm{~m}, h_{t 2}=0.58 \mathrm{~m}, h_{1}=2 \mathrm{~cm}, m_{b}=$ $1 \mathrm{~kg}, m_{b 2}-m_{b 1}=1 \mathrm{~kg}, V_{h}=300 \mathrm{~cm}^{3}, T_{a t m}=293 \mathrm{~K}, p_{a t m}=101.4 \mathrm{kPa}, g=9.81 \mathrm{~m} \mathrm{~s}^{-2}$. Errors calculated are specific to these gasometers, and would be different if other equipment was used.

To indicate how the shape of height and weight gasometers affects the error in the reported gas volume, values were calculated for aspect ratios between 10 and 200 (total gasometer volume constant at $10 \mathrm{I}$ ). For bottle type gasometers a range of cross-sectional areas from $50-500 \mathrm{~cm}^{2}$ was considered.

\subsubsection{Calibration of a gas flow meter}

Air was introduced into a gas flow meter with 4 parallel channels using a low flow peristaltic pump at flow rates between $1-250 \mathrm{I} \mathrm{d}^{-1}$. The air flow from each channel was collected in 10-litre gas sampling bag, and pumping continued until between 5-8 litres of air had been collected. The volume collected was measured using a weight type gasometer. The apparent volume of the gas counter bucket (STP ml count ${ }^{-1}$ ) was calculated for each channel at each flow rate. In a second trial, performed on a different bank of 4 gas counters, measurements were taken over eight runs carried out at the same flow rate $\left(\sim 7.5 \mathrm{I} \mathrm{d}^{-1}\right)$ to assess the variability in apparent bucket volume. These runs involved the measurement of 3.2-4.1 I of air and 143-210 counts.

For each experimental run the data were treated in two ways: in the first case the volume of gas passing through the bucket in each 5-minute period was corrected to STP using the ambient pressure and temperature recorded in the laboratory during that interval. In the second case the correction to STP was based on average ambient conditions during the 
run. The calibration was calculated using the volume of gas in the sampling bag measured in a weight gasometer corrected to STP. No correction was made for vapour content since ambient air was used in the experiment.

\subsection{Analytical methods}

Gas composition was measured using a Varian CP 3800 gas chromatograph (Varian Ltd, Oxford, UK) with a thermal conductivity detector, using a Heysep $\mathrm{C}$ column and argon as the carrier gas. Biogas composition was compared with a standard gas containing $65 \%$ methane and $35 \%$ carbon dioxide. Ambient air temperature and pressure were logged automatically at 5 minute intervals. The density of barrier solutions was checked by comparison with deionised water.

Gas volumes are quoted at STP of $273.15 \mathrm{~K}$ and $100 \mathrm{kPa}$.

\section{Results and Discussion}

\subsection{Diffusion of biogas through the barrier solution}

Results from the static batch test using acidified water $(\mathrm{pH} 2)$ as a barrier solution are shown in Figure 4. A rapid change in both volume and composition was noted over the test period. The methane concentration increased from 64.3 to $81.3 \%$ while carbon dioxide decreased from 33.6 to $12.0 \%$. The results also show dilution of the biogas by inward diffusion of air, with a decrease in biogas concentration to $93.3 \%$ over the 17-day period, and an air (nitrogen and oxygen) peak appearing in the GC profile after 5 days. Although the methane concentration increased due to carbon dioxide absorption, the absolute quantity of methane held in the column headspace decreased with time to around $96 \%$ of the starting value by the end of the test, indicating solubilisation and outward diffusion of methane. Less than $30 \%$ of the original carbon dioxide remained in the column headspace when the experiment was terminated. These results clearly demonstrate diffusion of gases in both directions through the barrier solution driven by the high partial pressures, and suggest that acidified water alone is not a suitable solution even for relatively short periods of storage.

Results from the comparison of different barrier solutions are shown in Figure 5. All of the other barrier solutions performed better than tap water, although acidified water and mineral oil showed considerable losses in carbon dioxide and up to $10 \%$ loss in methane over the test period. Saturated $\mathrm{NaCl}$ and acidified saturated $\mathrm{NaCl}$ showed similar results with the ability to retain $99 \%$ of methane and $92 \%$ of carbon dioxide in the gasometer during the test.

Use of a saturated saline solution leads to crystallisation of salt in and on experimental equipment, and from a practical point of view the use of a weaker solution may be preferable. Figure 5 shows the results for the four acidified saline solutions tested, with a clear trend of increasing carbon dioxide losses with decreasing ionic strength. The performance of the $75 \%$ saturated $\mathrm{NaCl}$ solution was comparable to that of the saturated solution, with $96 \%$ of the methane and $88 \%$ of the carbon dioxide remaining in the column headspace at the end of the 8-day test period.

In the test using a $3 \mathrm{M}$ solution of $\mathrm{NaOH}$, there was no observable change in the quantity of methane in the column headspace over a 10-day period. There was however evidence of inward diffusion as an air peak was noted in the GC profile after 5 days.

The experimental results are in agreement with those found in other studies. Muller et al. (Muller et al. 2004) tested three types of barrier solution, and also concluded that water 
acidified to $\mathrm{pH}<2$ is not appropriate as a barrier solution. The improved performance of saline solutions is due to the reduced solubility of gases, as the presence of dissolved solids leads to hydration ('solvation') of the solute, leaving less free solvent available for gas absorption (Umbreit et al. 1964). High ionic strength does not completely prevent gas from dissolving in the displaced liquid and diffusing into the surrounding atmosphere (Guwy 2004): this is particularly the case for carbon dioxide.

\subsection{Sensitivity analysis on the quantification of biogas volumes 3.2.1 Height and Weight Gasometers}

Need for correction factors. Analysis of equations 1 and 2 for sensitivity to corrections for STP, water vapour content, and hydrostatic pressure head shows how each is governed by a particular condition with a clear physical explanation, as summarised in Table 1.

The effect on the gas volume of ignoring the correction to STP is proportional to the ratio of pressures and temperatures involved. The vapour content of a saturated gas increases with increasing temperature, and is only influenced by this parameter. Figure 7 shows the error caused by ignoring this correction for a saturated gas at ambient pressure ( $\left.p_{h 2 o} / p_{\text {atm }}\right)$ over a range from $10-35^{\circ} \mathrm{C}$, typical of laboratory ambient temperatures. The importance of these corrections is therefore clear.

The hydrostatic pressure head correction is influenced by the height of liquid in the column, since the gas inside is at lower pressure when this height is greater. Measurements made near the top of the column and not corrected for this factor give an overestimate of gas volume. Starting from a position lower in the column, the effect is to underestimate gas volume. Figure 8 shows this variation, and shows that the error is larger in tall gasometers.

In addition, the hydrostatic pressure inside the column affects the proportion of the volume occupied by vapour. The actual volume occupied by vapour is proportional to the ratio of SVP to the pressure in the gasometer $\left(p_{2}\right)$, which is always at or below atmospheric pressure. This error is also larger in tall gasometers, since $p_{2}$ is lower. Figure 7 shows the effect for gasometers with different aspect ratios.

The hydrostatic pressure head within the column thus has a significant effect on the apparent gas volume and it is important that a suitable correction is applied.

Effect of measurement errors. Incorrect measurement or variations in the cross-sectional area of the gasometer also cause errors in gas volume calculations. There is a significant difference between the height and weight gasometers in this respect. In the height gasometer the error in volume is proportional to that in area, but the same error in area in a weight gasometer results in a much smaller error in volume, as shown in Figure 9 . The explanation for this is seen in equations 1 and 2 . In the height gasometer the area is used in the volume calculation, which depends on $A\left(h_{c 2}-h_{c 1}\right)$ multiplied by pressure correction terms, and thus errors in area are transmitted directly to the gas volume. This is not the case in equation 2, which can be simplified into three terms corresponding to the STP correction, the volume term, and the hydrostatic pressure correction (due to column height and vapour content), as shown in equation 6.

$$
V_{s t p}=\left(\frac{T_{s t p}}{T_{a t m} p_{s t p}}\right) \cdot\left(\frac{m_{b}}{\rho_{b}}\right) \cdot\left(\rho_{b} g h_{1}+p_{a t m}-p_{H_{2} O}\left(T_{a t m}\right)-\rho_{b} g\left(H-h_{1}-\frac{m_{b}}{A \rho_{b}}\right)\right)
$$

Equation 6 Rearrangement of the weight gasometer equation 
The cross-sectional area A appears only in the pressure correction term, and the volume term $m_{b} / \rho_{b}$ is independent of area, resulting in a desensitization of the equation to this parameter. The lack of sensitivity of weight gasometers to cross-sectional area errors is particularly useful since typical manufacturing tolerances mean this parameter is rarely exactly constant in one column or between different sets of apparatus.

Figure 10 shows how the gasometers are affected by a $1 \mathrm{~mm}$ error in measurement of $h_{c 1}$ or $h c_{2}$. Larger errors occur in gasometers with a low aspect ratio, as for similar gas volumes the difference term $\left(h_{c_{2}-} h_{c_{1}}\right)$ is smaller and thus the error is proportionally greater. It follows that appropriate sizing of height gasometers is important, as the smallest crosssection practically possible for the range of volumes to be measured will produce the smallest error. Unlike the variation caused by temperature, pressure, vapour content and hydrostatic head, this type of measurement error cannot be eliminated by applying a correction factor and is best minimised by correct design of equipment.

For the weight gasometer a $1 \mathrm{~mm}$ error in $h_{1}$ and a $10 \mathrm{~g}$ error in $m_{w}$ are considered as shown in Figure 10. The shape of the gasometer has very little effect on the error in gas volume. An incorrect measurement of $1 \mathrm{~mm}$ causes little error, since as noted above the height measurement in this type of gasometer is only used in the pressure correction part of the calculation. The $10 \mathrm{~g}$ error in the weight equates to an error of $1 \%$, simply because $m_{w}$ in these calculations was chosen as $1000 \mathrm{~g}$ of which $10 \mathrm{~g}$ is $1 \%$. In a weight gasometer the accuracy is therefore almost entirely dependent on the sensitivity of the balance used, and geometry/size and errors in cross sectional area have little impact on the calculated gas volume. Even a large diameter weight gasometer can be used to measure small volumes of gas, if a sufficiently sensitive balance is used.

\subsubsection{Bottle Gasometers}

The effects of correction to standard temperature and pressure and for vapour content on the bottle type of gasometer are similar to those described above for height and weight gasometers. Unlike height or weight gasometers, however, in the bottle gasometer the gas is under a slight positive pressure exerted by the head of liquid in the tube that allows displacement into the second container. This means that the required correction for hydrostatic pressure head increases with the height difference between the outlet to the second container and the liquid level. Figure 11 shows the error in gas volume with starting liquid height and cross-sectional area, which increases not only with height (hydrostatic pressure head) but also with cross-sectional area. The relationship with crosssectional area appears because the volumes measured are constant in this analysis and therefore $h_{2}$ is greater where $A$ is smaller, leading to a greater pressure head exerted on the measured gas.

Figure 12 shows how errors in the measurement of height and weight affect the gas volume depending on the cross-sectional area of the bottle gasometer. Errors considered are $1 \mathrm{~mm}$ in the measurement of $h_{1}$ and $10 \mathrm{~g}$ in the weight $\left(m_{b 2}-m_{b 1}\right)$. The nature of the error when calculated using the height and weight-based methods, as shown in equations 3 and 4 respectively, is similar to that in height and weight gasometers as discussed in section 3.2.1. Using the height-based method therefore requires appropriate sizing of the bottles to ensure that likely errors in the height measurement are small relative to $\left(h_{2}-h_{1}\right)$ for the volumes of gas measured. On the other hand the weight-based method shows minimal transmission of errors in height measurement to the final gas calculation, as 
heights are used only for a minor pressure correction rather than as the main way of ascertaining volume. The analysis for Figure 12 involved a constant mass $\left(m_{b 2}-m_{b 1}=1\right.$ $\mathrm{kg}$ ) in which the $10 \mathrm{~g}$ error is $1 \%$, which is transferred proportionally to the volume. For the weight-based method a balance with appropriate sensitivity must therefore be used whereas errors in height measurement are less critical.

\subsection{Calibration of the gas flow meter}

The results from the gas flow meter experiment can be seen in Figure 13, which shows both the full range of flow rates tested and the design flow range for this counter. The main observations were firstly that each counter channel, although manufactured to the same specification, had a different calibration value; and secondly that the counter calibration had an obvious flow rate dependency, with the volume per count increasing with flow rate. The relationship between calibration and flow rate was approximately linear with gradients of 0.0211-0.0286 ml count ${ }^{-1}\left(\mathrm{day}^{-1}\right)^{-1}$ and $\mathrm{R}^{2}$ of $0.949-0.986$. This dependency can be explained by the fact that gas flow continues during the time taken for the bucket to tip, and a small quantity of gas is not captured: the greater the flow rate, the larger the volume unmeasured. Over the design flow rate range for the flow meter this dependency is equivalent to a difference of $0.422-0.572 \mathrm{ml}^{\text {count }}{ }^{-1}$ which gives a maximum error of $3.0 \%$ (based on $19.09 \mathrm{ml} \mathrm{count}^{-1}$, channel 4). In practice a correction factor could be included in calculations, thus reducing or eliminating the error from this source.

At a single flow rate the calibration of the flow meter channels showed some variation over 8 runs. The average values were 20.1, 22.9, 21.1 and 20.3 STP ml count ${ }^{-1}$ with standard deviations of $1.5 \%, 1.9 \%, 1.6 \%$ and $2.5 \%$ for channels $1-4$ respectively. The differences were checked for correlations with ambient temperature and pressure but none was found. The variation could be because the gas flow meters have a discrete unit of measurement which is the amount of gas needed to tip the bucket. Additionally, during temperature transitions the temperature of the liquid in the flow meter may lag behind ambient air temperature, causing the gas in the counter to be at a slightly different temperature and altering the correction factor for STP conditions.

Regarding the two STP correction methods, agreement was within an average $0.49 \%$ (S.D. $0.56 \%$ ) over 20 trials ranging in length from 23 to 7162 minutes. Figure 14 shows how the percentage difference between the two methods correlates closely to that between the average ratio of pressure to temperature. This occurs because the flow rate in the experiments was constant, and thus periodic correction for atmospheric conditions is almost equivalent to correction for time-averaged atmospheric conditions.

The simple calibration method, where the volume is corrected based on the end-of-run values for temperature and pressure, should be avoided where possible since it introduces an error which may be large where the end temperature and pressure are significantly different from average values over the run. Where possible the gas flow meters should be corrected to real time atmospheric conditions. Where this is not possible time-averaged values of temperature and pressure should be used to correct gas flow data, although errors may be introduced where flow rates change significantly through the sampling period, as may be the case for example in semi-continuous digestion experiments with substrate added once per day.

The results demonstrate that provided corrections are made for the flow rate dependence of the instrument and real time or time-averaged conversion of gas volumes to STP is performed, the gas flow meter can provide gas volumes well within the tolerance of $5 \%$ suggested by the original designers (WRC 1975). 


\section{Conclusions}

Biogas production is of key importance in anaerobic digestion experiments but errors in its quantification can arise unless two essential issues are properly considered: the method for collecting the biogas/methane produced without significant losses or errors, and the method for converting the observed biogas/methane production to that under STP conditions using suitable correction/calibration factors.

Biogas not only dissolves into barrier solutions, but tends to permeate through these into the atmosphere because the partial pressures of methane and carbon dioxide in the atmosphere are much lower than in the collection column. Conversely, oxygen and nitrogen can diffuse into the collection column. The speed of diffusion is a function of the solubility of gases in the barrier solution, and therefore solutions with high ionic content are most suitable. Acidified saturated $\mathrm{NaCl}$ solution was most effective in preserving the composition and volume of biogas when compared with other liquids/solutions such as tap water, acidified water, mineral oil and saturated $\mathrm{NaCl}$ solution. Since using saturated solutions is problematic, a $75 \%$ saturated acidified solution may be preferred and provides almost the same benefit. Despite the use of barrier solutions with low gas solubility, gas exchange still occurs and therefore frequent sampling of the biogas composition and volume is advised.

The conversion of gas volumes to STP requires correction of measurements made in height, weight and bottle gasometers in accordance with equations 1-4 shown above. The accuracy of weight gasometers depends mainly on the sensitivity of the balance used and errors in cross-sectional area or height measurements result in only small errors in calculated gas volume. Height gasometers have two disadvantages: they require appropriate sizing to the volumes of gas measured to ensure accurate measurements and over longer contact periods may also allow gas to diffuse through the barrier solution.

Gas flow meters as used in this work were capable of providing gas flow and volume data at a single flow rate to well within the $5 \%$ accuracy quoted in the original design (WRC 1975). There is an approximate linear dependency between flow rate and flow meter calibration, and thus either in-situ calibration or average flow rate calibration is advised for this equipment. Gas flow meters should be calibrated to STP in real time if possible to correct for changing atmospheric conditions as well as variations in flow rate; if this is not possible, average conditions over the period of operation should be used to correct to STP.

\section{Acknowledgements}

The authors wish to express their thanks for the support of Dr Andrew Salter in writing computer software for gas counters and gas measurement devices.

\section{References}

BS (2004). BS ISO 15985:2004 Plastics - Determination of the ultimate anaerobic biodegradation and disintegration under high-solids anaerobic-digestion conditions Method by analysis of released biogas.

BS (2005). BS ISO 14853:2005 Plastics - Determination of the ultimate anaerobic biodegradation of plastic materials in an aqueous system - Method by measurement of biogas production.

EA (2005). Guidance on monitoring MBT and other pre-treatment processes for the landfill allowances schemes (England and Wales), The Environment Agency, UK. 
Goff, J. A. and S. Gratch (1946). "Low pressure properties of water from -160 to 212 degrees F." Transactions of the american society of heating and ventilation engineers: 347-354.

Guwy, A. J. (2004). "Equipment used for testin ganaerobic biodegradability and activity." Reviews in Environmental Science and Biotechnology 3(2): 131-139.

James, A., C. A. L. Chernicharo and C. M. M. Campos (1990). "The development of a new methodology for the assessment of specific methanogenic activity." Water Research 24(7): 813-825.

Kida, K., T. Shigematsu, J. Kijima, M. Numaguchi, Y. Mochinaga, N. Abe and S. Morimura (2001). "Influence of $\mathrm{Ni2}+$ and $\mathrm{Co2}+$ on methanogenic activity and the amounts of coenzymes involved in methanogenesis." Journal of Bioscience and Bioengineering 91(6): 590-595.

Liu, J., G. Olsson and B. Mattiasson (2004). "A volumetric meter for monitoring of low gas glow rate from laboratory-scale biogas reactors." Sensors and actuators $B$ chemicals 97(2-3): 369-372.

Luostarinen, S., S. Luste and M. Sillanpää (2009). "Increased biogas production at wastewater treatment plants through co-digestion of sewage sludge with grease trap sludge from a meat processing plant." Bioresource Technology 100(1): 79-85.

McCarty, P. L. (1964). "Anaerobic waste treatment fundamentals III." Public Works 95: 9194.

McNaught, A. D. and A. Wilkinson (1997). Compendium of chemical terminology (2nd ed.), Blackwell Scietific Publications.

Muller, W.-R., I. Frommert and R. Jorg (2004). "Standardized methods for anaerobic biodegradability testing." Reviews in Environmental Science and Biotechnology 3(2): 141-158.

NBS (1982). "Table of chemical thermodynamic properties, National bureau of standards." Journal of physics and chemical reference data 11(2).

Nilsson, B. K., I. Bjerle and H. T. Karlsson (1988). "A simple meter with zero pressure-drop for gas-flows." Industrial and engineering chemistry research 27(8): 1553-1555.

Rozzi, A. and E. Remigi (2004). "Methods of assessing microbial activity and inhibition under anaerobic conditions: a literature review." Reviews in Environmental Science and Biotechnology 3(2): 93-115.

Schonberg, J. C., S. K. Bhattacharya, R. L. Madura, S. H. Mason and R. A. Conway (1997). "Evaluation of anaerobic treatment of selected petrochemical wastes." Journal of Hazardous Materials 54(1-2): 47-63.

Smith, J. A. and C. M. Carliell-Marquet (2008). "The digestibility of iron-dosed activated sludge." Bioresource Technology 99(18): 8585-8592.

Soto, M., R. Mendez and J. M. Lema (1993). "Methanogenic and non-methanogenic activity tests. Theoretical basis and experimental set up." Water Research 27(8): 1361-1376.

Sponza, D. T. (2003). "Toxicity and treatability of carbontetrachloride and tetrachloroethylene in anaerobic batch cultures " International Biodeterioration and Biodegradation 51(2): 119-127

Umbreit, W. W., R. H. Burris and J. F. Stauffer (1964). "Manometric techniques: a manual describing methods applicable to the study of tissue metabolism." Minneapolis, Burgess: 5 .

WRC (1975). "Equipment for Measurment of Gas Prodcution at Low Rates of Flow Technical Memorandum TM104 - Water Research Centre."

Yang, J. and R. E. Speece (1986). "The effects of chloroform toxicity on methane fermentation." Water Research 20(10): 1273-1279. 
a) Condition 1

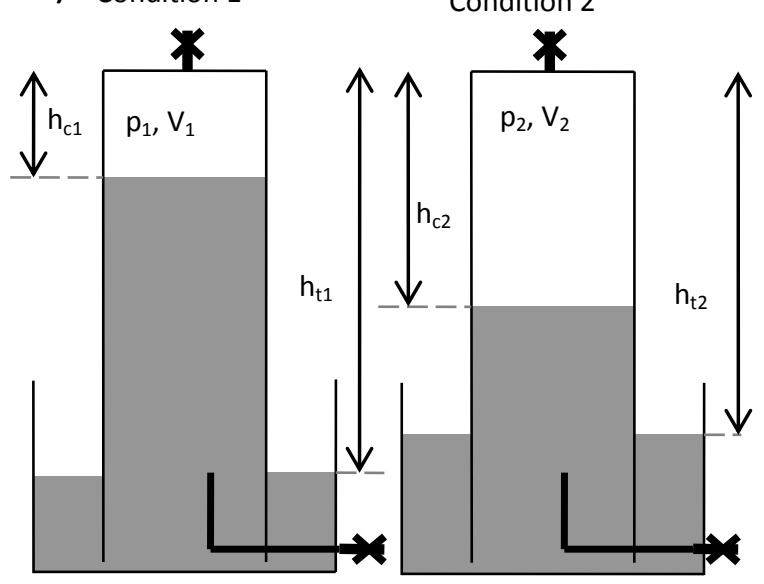

c)

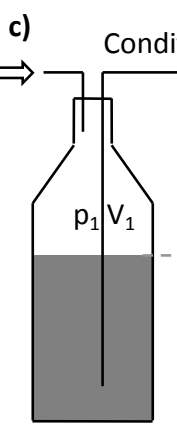

Condition 2

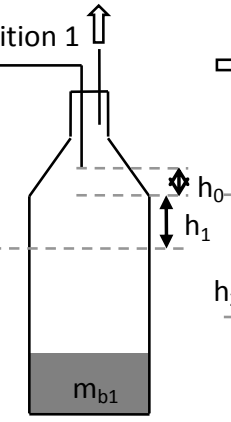

b) Condition 1
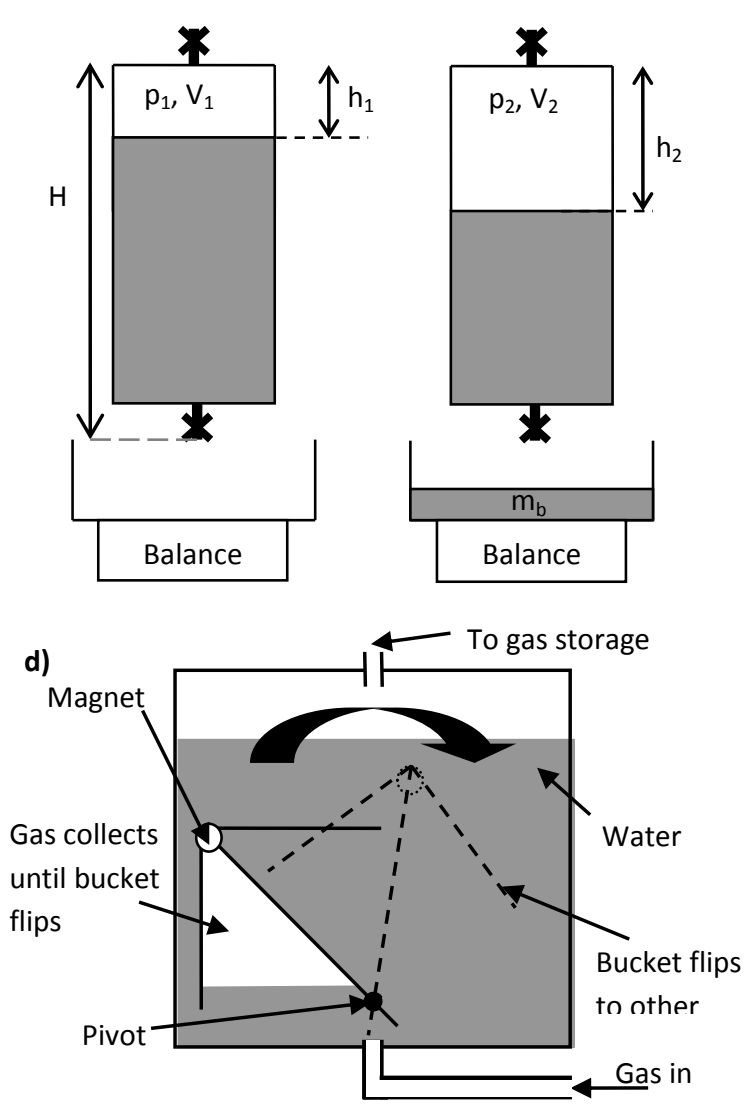

Figure 1 Equipment design a) trough gasometer, b) weight gasometer, c) bottle gasometer, d) gas flow meter
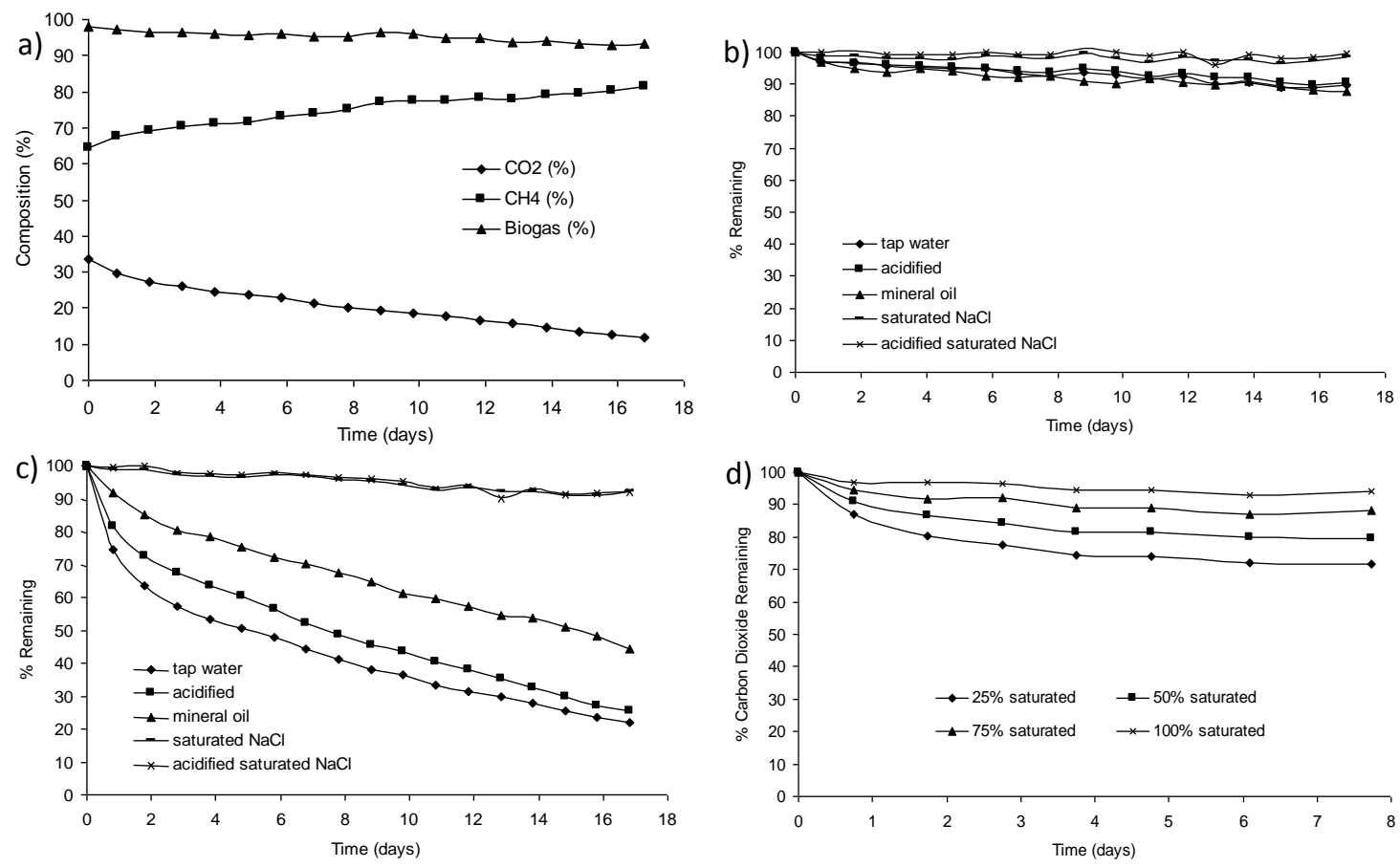

Figure 2 Trends of biogas retention in trough gasometers over time a) biogas composition with acidified water, b) methane retention with various barrier solutions, c) carbon dioxide retention with 
various barrier solutions, d) carbon dioxide retention with varying concentration of acidified $\mathrm{NaCl}$ solution.
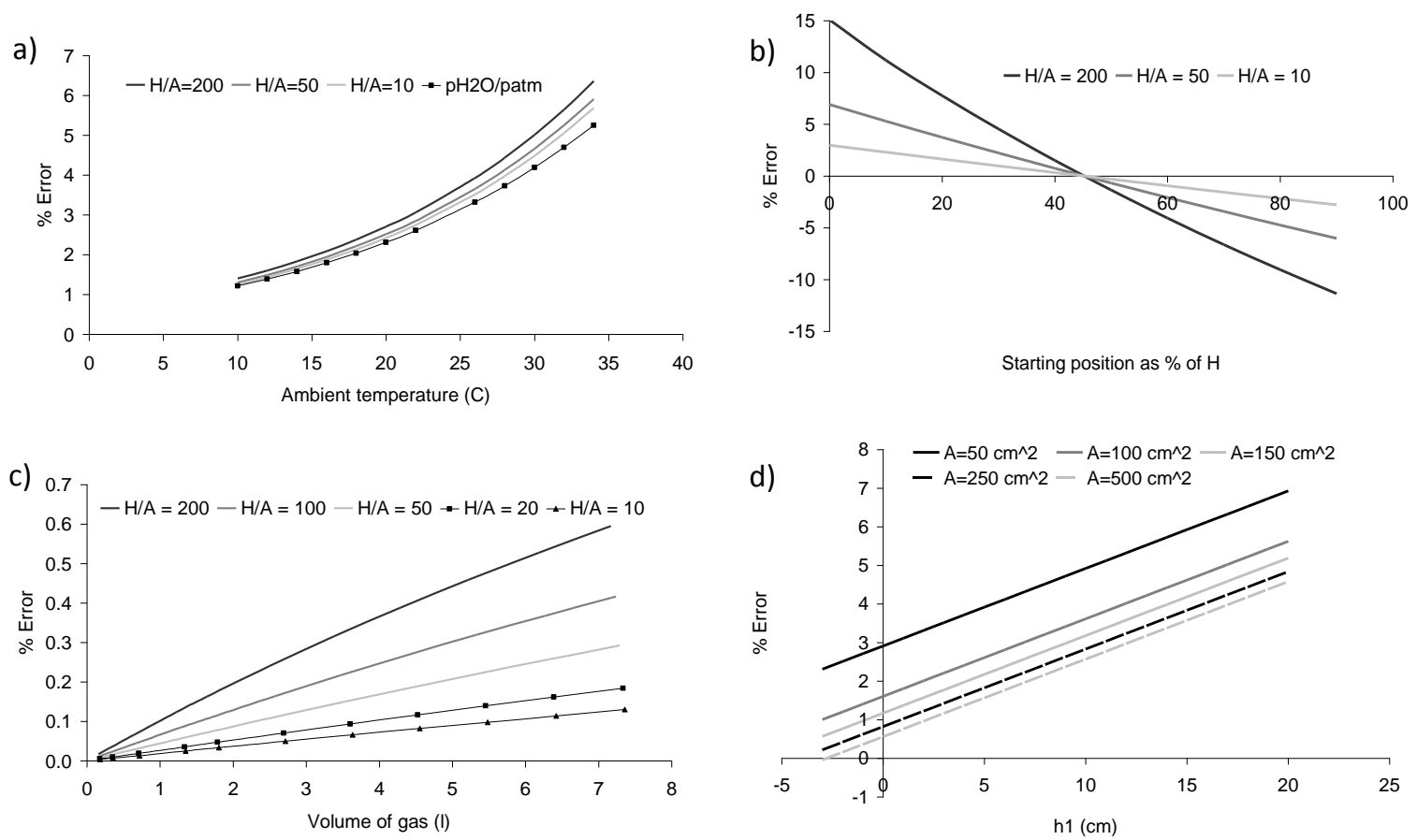

Figure 3 Errors in gas measurements associated with incorrect calculation methods a) Temperature correction in weight gasometers, b) column height correction in weight gasometers, c) $5 \%$ error in cross sectional area in weight gasometers, d) liquid level correction in bottle gasometers.
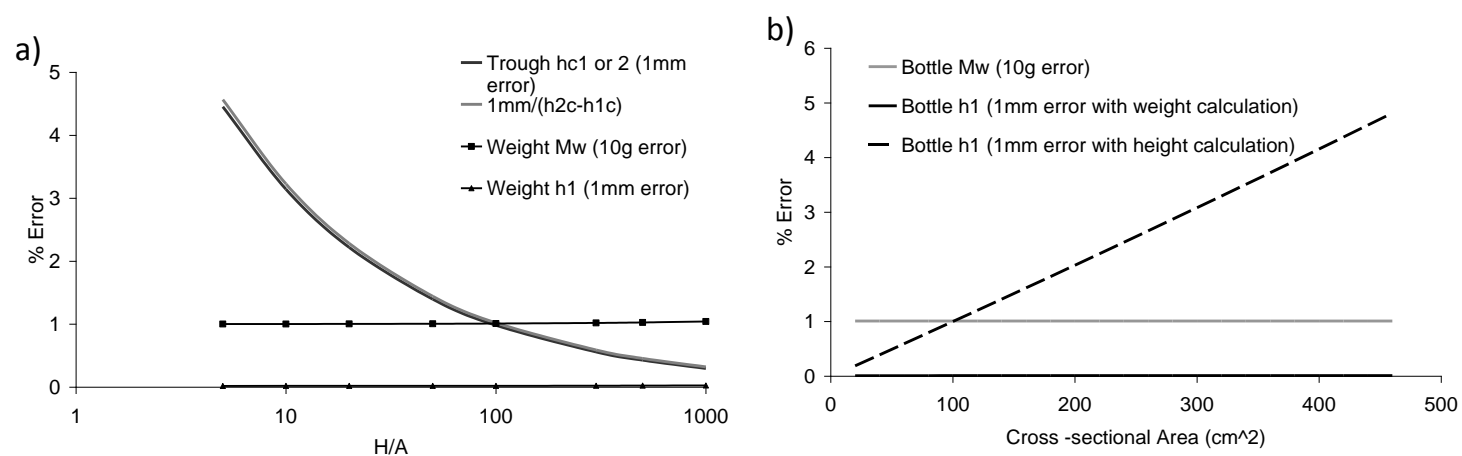

Figure 4 Errors in gas measurement caused by errors in readings a) comparison of trough and weight gasometers (for height type $\left.A\left(h_{c 2}-h_{c 1}\right)=0.001 \mathrm{~m}^{3}\right)$, b) comparison of calculation method in bottle gasometers $\left(m_{b 2}-m_{b 1}=1 \mathrm{~kg}\right)$.
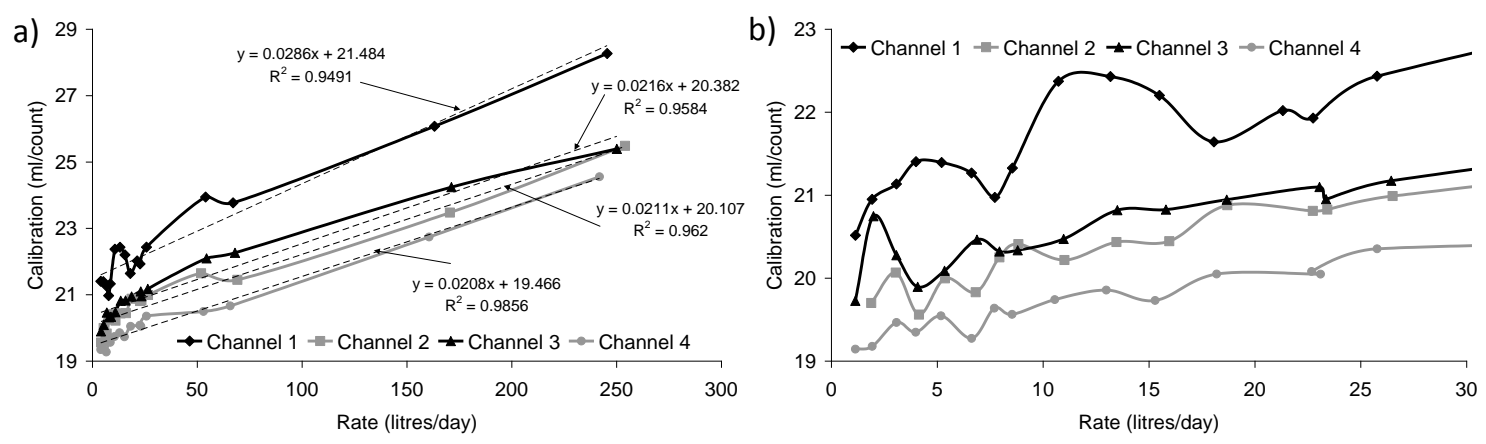
Figure 5 Calibration of a four channel gas flow meter a) flowrates $0-300$ litres per day, b) flowrates 030 litres per day.

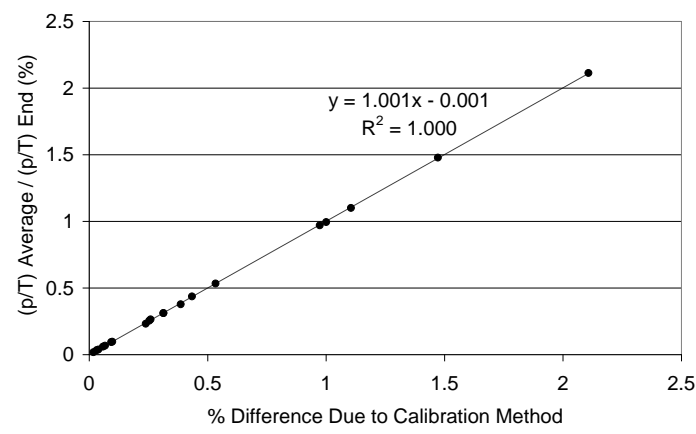

Figure 6 Comparison of gas flow data correction to average and end atmospheric conditions

Table 1. Governing Characteristics of Gas Volume Calculation Errors

Neglected correction Major Governing Comments

Characteristic

$\begin{array}{lll}\begin{array}{l}\text { Standard temperature and } \\ \text { pressure }(273.2 \mathrm{~K}, 100 \mathrm{kPa})\end{array} & \frac{p_{a}}{T_{a}}: \frac{p_{s t p}}{T_{s t p}} \quad \text { Error is proportional to the ratio }\end{array}$

Vapour in biogas $\quad$ Ambient temperature Overestimate of gas volume

Hydrostatic pressure head $\quad h_{c 1}$, or $h_{1} \quad$ Overestimate of gas volume due to the column of liquid in $h_{c 1}$, or $h_{1}$ near the top of the gasometer the gasometer underestimate at the bottom 